\title{
PRIMARY RADIO-FREQUENCY STANDARDIZATION BY USE OF THE CATHODE-RAY OSCILLOGRAPH.
}

\author{
By Grace Hazen and Frieda Kenyon.
}

ABSTRACT.

A method of high accuracy has been developed for the primary standardization of radio-frequency. Comparison is made between a tuning fork of accurately known frequency with an electron-tube drive and a generating set of radio-frequency current by the use of two radio-frequency generating sets and Lissajous figures produced in a cathode-ray oscillograph.

The apparatus used in this work consisted of a Bureau of Standards type $\mathrm{R}_{7} \mathrm{OB}$ wave meter which has a variable air condenser, 4 fixed mica condensers and 5 interchangeable inductors, a tuning fork of $1,024.2$ cycles per second driven by a 5 -watt electron-tube generating set, 2 radio-frequency generating sets each using a 250 -watt electron tube, a cathode-ray oscillograph having a tube of the cold cathode type requiring from 18,000 to 20,000 volts to operate. The Lissajous figures were formed on the fluorescent screen by the alternating electric fields from two generating sets applied at right angles to each other and to the electron stream by means of condenser plates mounted on the tube.

The procedure adopted was to adjust the second of the radio-frequency generating sets to a known multiple of the tuning-fork frequency by the use of the Lissajous pattern ratio produced in the cathode-ray oscillograph. The wave meter was then brought into resonance with the radio-frequency generating set and read for the known frequency. A range from $\mathrm{x} / 2$ to 22 times the tuning-fork frequency was covered in this manner. The third radio-frequency generating set was then adjusted to a known multiple of the second generating set, still using the cathode-ray oscillograph. Radiofrequencies up to 22 times the second generating-set frequency were determined. The wave-meter circuit thus standardized was used as a basis for higher-frequency work. The second or lower-frequency generating set was set at a definite frequency from this standardized circuit, and the higher-frequency generating set adjusted to a multiple of it by means of the Lissajous figures.

The range of the wave meter standardized in this manner is from 3.5 to 5,000 kilocycles per second.

\section{CONTENTS.}

Page.

I. Introduction . . . . . . . . . . . . .

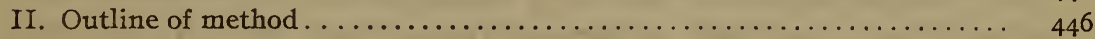

III. Apparatus . . . . . . . . . . . . .

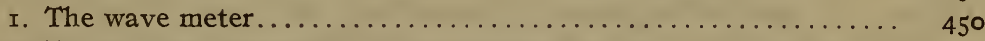

2. The tuning-fork controlled generating set............... $45^{\mathrm{I}}$

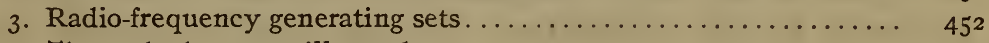

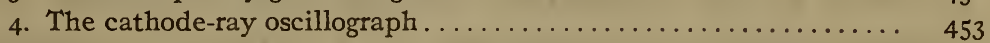

IV. Procedure . . . . . . . . . . . .

x. Direct comparison with tuning fork for low-frequency standardiza-

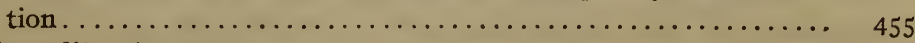

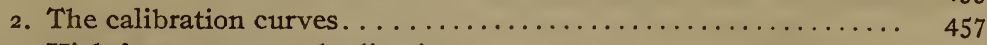

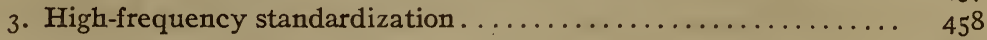

4. Observational difficulties......................... 460

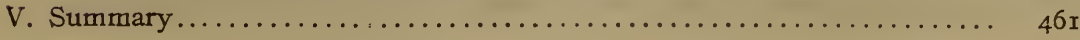




\section{INTRODUCTION.}

A method for primary standardization of radio-frequencies is described in this paper. The method involves a highly accurate comparison of the frequency of a tuning fork with a radio-frequency by means of a cathode-ray oscillograph.

This method had its origin in some experiments performed by L. M. Hull ${ }^{1}$ in this laboratory in I9r9. He showed that two radio-frequency generating circuits could be maintained suffciently constant to produce and maintain a definite pattern on the screen of a cathode-ray oscillograph; that is, better than I cycle per second in 500,000 cycles per second. The use of the cathode-ray oscillograph in a similar manner to compare a radio and an audio frequency was then undertaken by Dr. G. Breit and later by R. T. Cox under the direction of Dr. J. H. Dellinger. Doctor Breit and Mr. Cox left the Bureau of Standards while the work was under way, and it was carried to completion by the present authors under Doctor Dellinger's direction.

The purpose of this work was the establishment of absolute values of radio-frequencies in terms of the easily measurable audio-frequency with which they were compared by the cathoderay oscillograph. The results obtained have been verified by comparison with results obtained by several other methods, ${ }^{2}$ including measurement at low frequencies of inductance and capacity and calculations from these measurements, the multivibrator using a tuning-fork frequency and harmonics, and measurements of actual length of very short waves on parallel wires stepped down to the usual radio range by the use of harmonics.

\section{OUTLINE OF METHOD.}

The standardization was based on an audio-frequency standard produced by a carefully calibrated tuning fork with electron-tube drive. A radio-frequency generating set was adjusted to exact multiples of this audio-frequency by the use of Lissajous figures produced by the application, through small condenser plates, of voltages of the two frequencies to a cathode-ray oscillograph. The wave meter being standardized was then read for the known frequency of the radio-frequency generating set.

\footnotetext{
${ }^{1}$ L. M. Hull, "The cathode-ray oscillograph and its application in radio work," Proc. I. R. E., 9, p. I30; I921.

2“"Reducing the guesswork in tuning," by J. H. Dellinger, Radio Broadcast, 3, p. 242, July, I923.
} 
The wave meter consists of a variable air condenser with fixed mica condensers, which can be connected in parallel with it, and six interchangeable inductance coils. The resonance circuit and current-indicating device are shown in Figure $\mathrm{I}$. A standard tuning fork having a frequency of $\mathrm{r}, 024.2$ cycles per second was

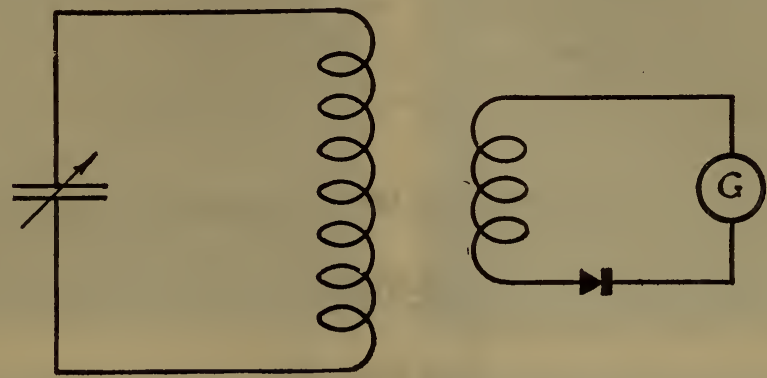

FIG. I.-Circuit diagram of the wave meter and resonance indicator.

The wave meter has six interchangeable inductors, and four fixed mica condensers which may be added in parallel to the variable condenser.

used. The fork is driven by an electron-tube generating set without mechanical contact, as shown schematically in Figure 2 . The circuit is so designed that it can be tuned to resonance with the fork. The apparatus ${ }^{3}$ is described briefly in Section III, 2, and in detail in an article by Eckhardt, Karcher, and Keiser.

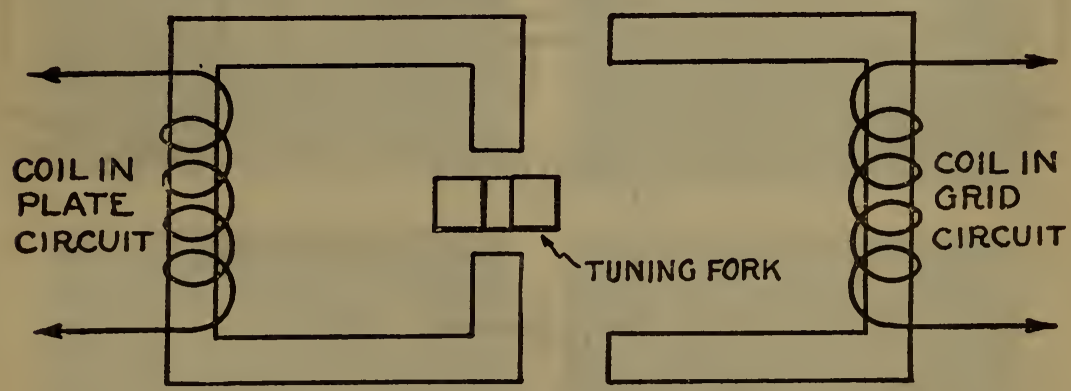

Fig. 2.-Schematic circuit diagram of the tuning-fork drive.

A transformer connected across the coil in plate circuit produces the voltage of the tuning-fork frequency in the cathode-ray oscillograph.

A transformer across the coil in the plate circuit serves to produce a voltage of this frequency on one set of electrostatic deflecting plates mounted on the cathode-ray oscillograph. The diagram of apparatus as assembled is shown in Figure 3. The other plates

3 "An electron-tube tuning fork drive," by E. A. Eckhardt, J. D. Karcher, and M. Keiser. Jour. Opt. Soc. of Amer., Z, p. 949, November, r922.

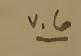


on the cathode-ray tube are connected to a second electrontube generating set. The cathode-ray stream, ordinarily appearing as a bright spot on the fluorescent screen of the tube, is deflected in a horizontal direction by the voltage on one pair of deflecting plates and in a vertical direction by the voltage on the other plates. When the two voltages are applied at the same time, a blurred rectangle appears except when there is a simple ratio between the two, then a Lissajous figure showing this ratio appears (fig. 4).

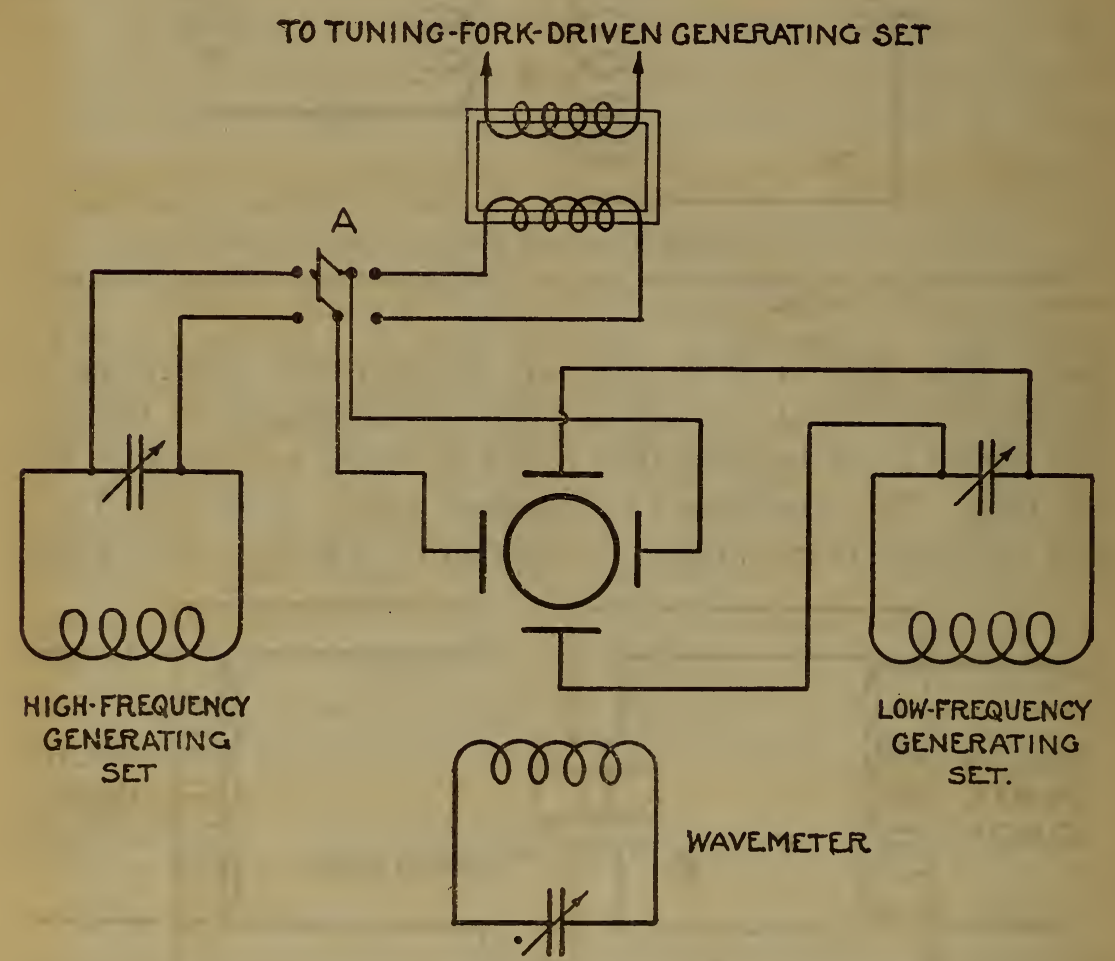

FIG. 3.-Arrangement of the apparatus used for primary frequency standardization. With this arrangement the wave meter can be coupled to either generator by a slight turn.

By means of these Lissajous figures, the second or low-frequency generating set can be adjusted very accurately to known multiples of the tuning-fork frequency. The wave meter is then tuned to resonance with the low-frequency generating set, the setting of the variable condenser being read for this known frequency. In this manner wave-meter settings were found for frequencies between 3.5 and 20 kilocycles per second. To reach higher frequencies, a third or high-frequency generating set was used. The lowfrequency generating set was adjusted in the usual manner to 
Scientific Papers of the Bureau of Standards, Vol. 19

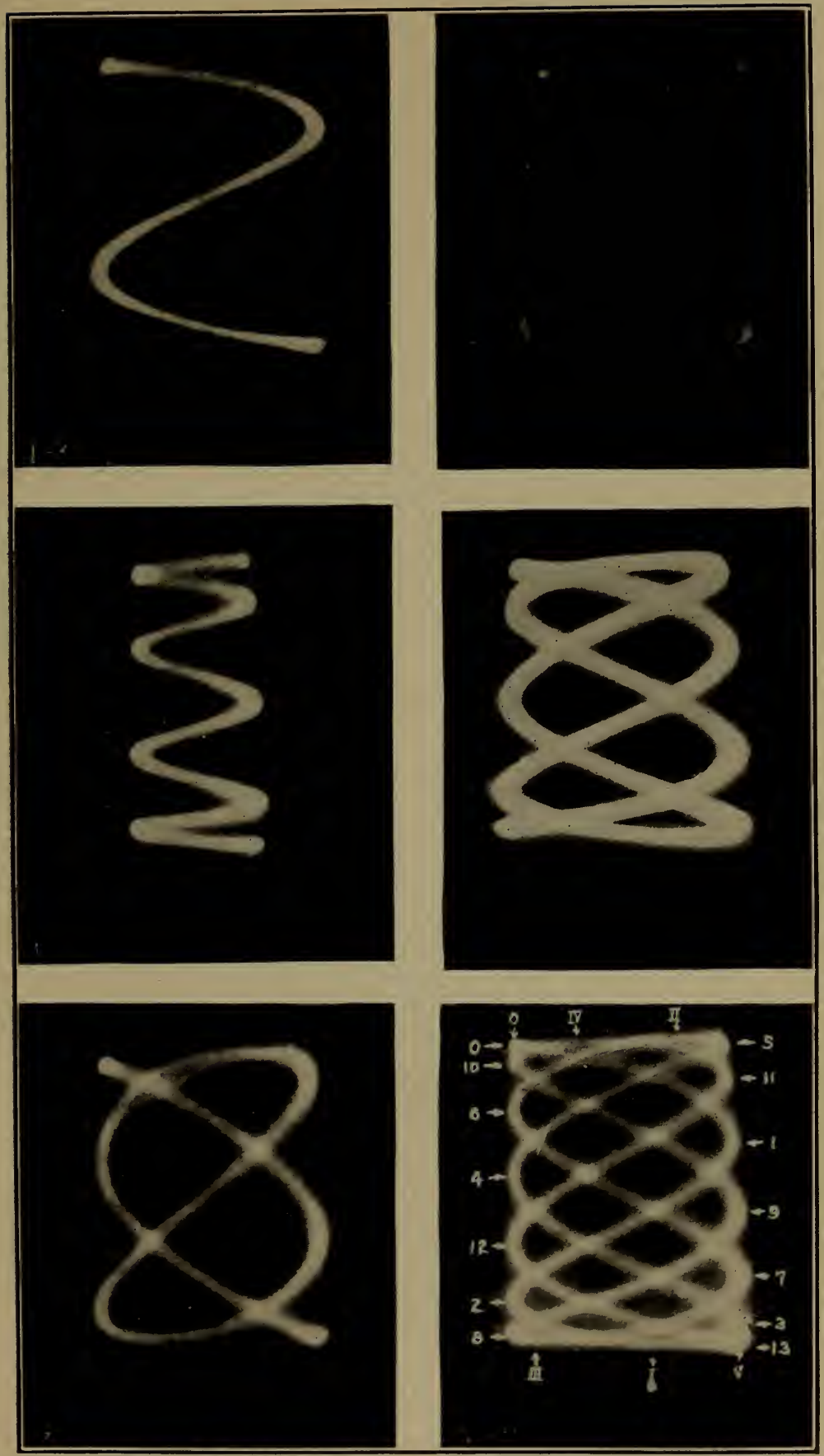

FIG. 4.-Photograph of Lissajous figures of various ratios. 


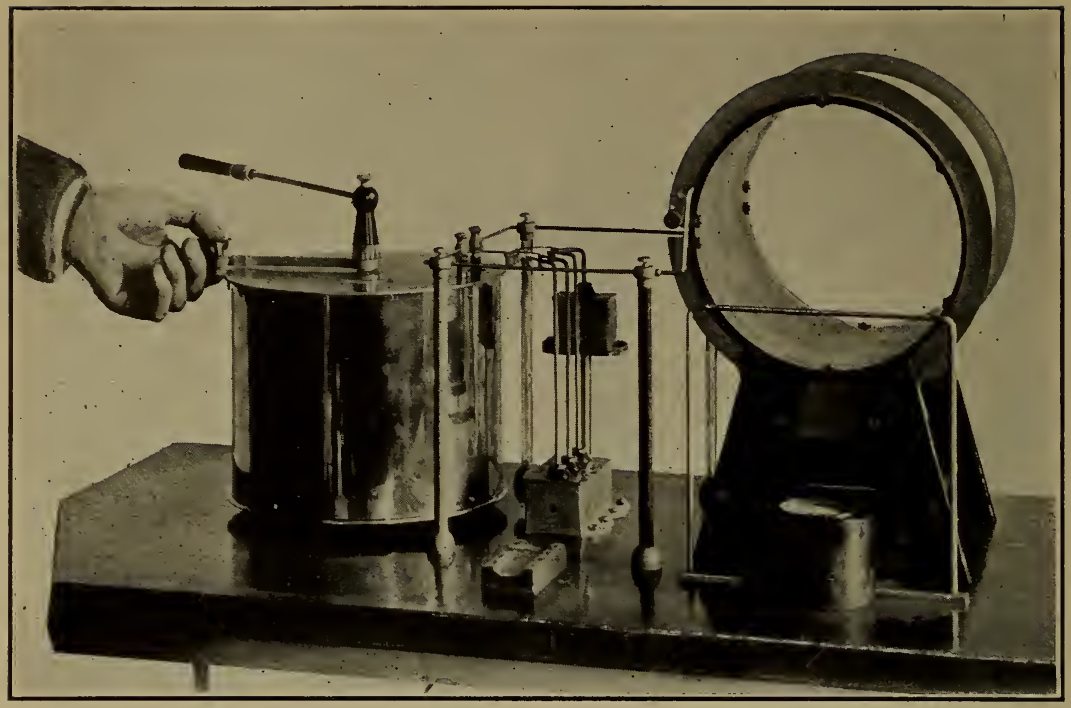

Fig. 5.-The standard wave meter.

A wall galvanometer and crystal detector replaced the detector shown in the picture.

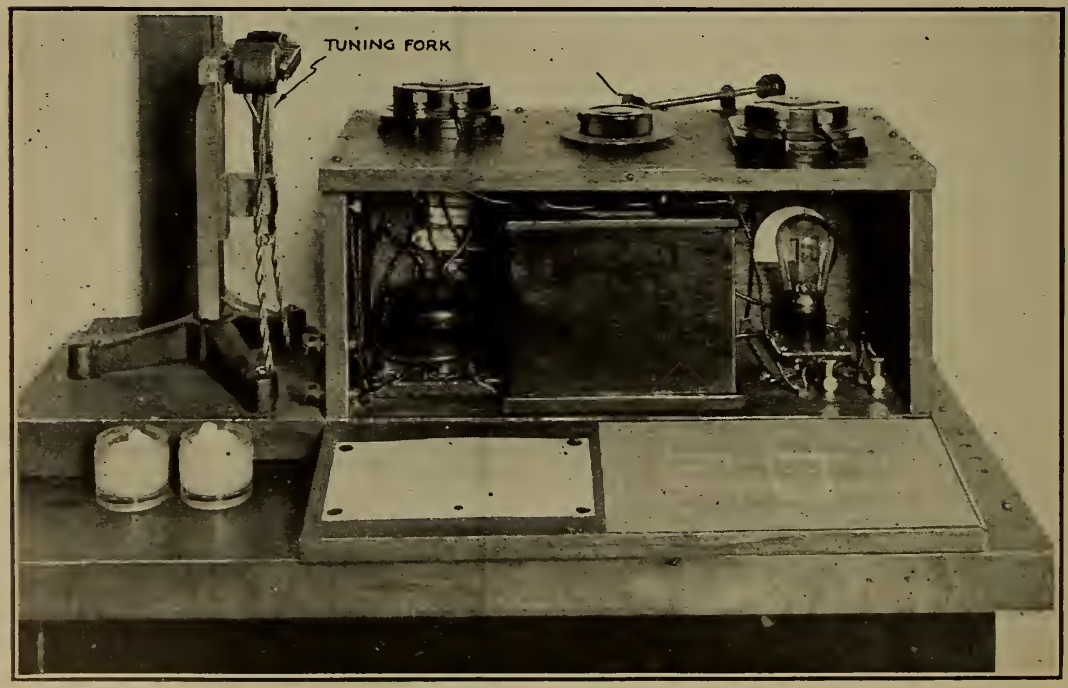

- FIG. 6.-The electron-tube drive for tuning fork.

The electron-tube circuit is tuned to the frequency of the fork as shown by the presence of zero beat between the impressed and natural frequency of the fork. 
the desired multiple of the tuning fork, a switch thrown disconnecting the tuning fork from the oscillograph and bringing the high-frequency voltage to the oscillograph on the plates perpendicular to the plates having the low-frequency voltage. Then the high-frequency generating set was adjusted to a known multiple of the low-frequency generating set, again using the cathode-ray oscillograph to determine the ratio. The range was thus extended to over 400 kilocycles per second. For higher frequencies the coil of 392 microhenries inductance with the variable air condenser formed the standardized circuit of frequencies from 450 to 620 kilocycles. The low-frequency generating set was adjusted to some frequency within its range, and the high-frequency generating set tuned to a multiple using the cathode-ray oscillograph and Lissajous figures as before described. The calibration was extended to a frequency of 4,900 kilocycles per second in this manner. Since frequencies from the Lissajous figures were at considerable intervals, calibration curves were drawn for the wave meter thus standardized by calculating the distributed capacity of the coil and leads and its pure inductance to obtain intermediate points. The procedure used is given in detail in Section IV, 2. By this means calibration curves were drawn from I3.I to 4,900 kilocycles.

The range now standardized was that of the variable air condenser in connection with each of the six coils. Fixed mica condensers of $0.00 \mathrm{I}$ to $0.015 \mu \mathrm{f}$, however, connected in parallel with the variable condenser increased the range on the low-frequency side of 3.5 kilocycles. Here the calibration curve was plotted directly, for the capacity of the mica condensers could not be considered independent of the frequency. Frequencies obtained by direct comparison with the tuning-fork generating set, being integral or simple functional multiples of the tuning-fork frequency, were widely separated as regards percentage, and it was necessary to obtain intermediate-frequency readings in order to draw the curve. This was done by stepping down, still using Lissajous figures, from the previously calibrated circuit, of coil and condenser having a range of $\mathrm{I} 3 . \mathrm{I}$ to 38 kilocycles. The calibration from 3.5 to 4,900 kilocycles was thus completed. 


\section{APPARẢTUS.}

\section{THE WAVE METER.}

The wave meter ${ }^{4}$ used in this standardization is designated as a Bureau of Standards wave meter, type R7oB. It is shown in Figure 5. The circuit contains variable condensers and interchangeable inductors. The variable air condenser is of the type described in Bureau of Standards Circular No. 74 with some modifications. It has a maximum capacity of $0.0012 \mu \mathrm{f}$. The resistance is negligible, due to the elimination of solid insulating material excepting the three short Pyrex glass rods which insulate the fixed plates from the moving plates and case. The condenser has a capacity calibration curve which is practically linear from 5 to $170^{\circ}$. The dielectric is almost entirely air. A slow-motion device permits fine adjustments of the condenser to be made. The scale of the condenser is read by a vernier and the condenser scale is continued to $190^{\circ}$ in order that readings may be made between 171 and $180^{\circ}$. There are four fixed mica condensers of $0.001,0.002,0.004$, and $0.008 \mu \mathrm{f}$, respectively, which can be connected in parallel with the variable condenser singly or in any desired combination. The shields of both variable and mica condensers are grounded through a metal post which extends through the carriage top on the low potential side of the wave meter. The condenser leads terminate in binding posts in which the terminals of the inductors fit and can be firmly clamped.

The inductors used with this wave meter are six coils. Five of these are single-layer coils ${ }^{5}$ of hexagonal cross section. They are wound on frames of laminated phenolic material made as open in construction as strength permits, giving the coils air cores in as far as possible. They are wound with silk-covered radio-frequency cable, each strand of which was tested for continuity. The coils have an average ratio of coil diameter to length of winding of about 2.r. These coils have inductances of approximately 10, $57,392,2,460$, and 5,440 microhenries, respectively. A coil of higher inductance was of five layers of radiofrequency cable on a Pyrex glass cylinder. It has an inductance of 127,000 microhenries. Bank winding was employed to decrease its distributed capacity. Four of the high-frequency coils were boxed to prevent injury in handling.

1For a detailed description see "Standard wave meter, Bureau of Standards type R7oB," by R. T. Cox. Jour. Opt. Soc. Amer., 6, p. 162, March, 1922.

${ }^{5}$ Bureau of Standards Circular No. 74 , "Radio Instruments and Measurements," and Bureau of Standards Letter Circular No 103. "Description of a series of single-layer inductance coils suitable for radiofrequency standards." 
A circuit consisting of a crystal detector and sensitive wall galvanometer served to indicate resonance. The indicating circuit was coupled to the four higher-frequency coils by a single turn of one-eighth-inch brass rod, and to the two lower-frequency coils by one and three turns of No. 14 wire, respectively.

The wave meter is mounted on a strong truck with rubbertired, ball-bearing swivel wheels. The variable and fixed condensers as well as the lead supports are fastened to the top. Arrangement is also made for clamping the coupling loops of the indicating device and crystal detector to the top of the truck. The frame was grounded when measurements were made.

\section{THE TUNING-FORK CONTROLLED GENERATING SET.}

The tuning-fork controlled generating set giving the fundamental frequency is shown in Figure 6 . The tuning fork used in this was standardized by the sound section of this bureau. The measurements were made with an oscillograph and chronometer before it was used, and again after the work was completed. The results of careful determinations gave a frequency of $\mathrm{I}, 024.2$ vibrations per second at $20^{\circ} \mathrm{C}$. The coefficient of frequency change with temperature was taken as -o.or I per cent per degree centigrade. This is the temperature coefficient established for carbon-steel tuning forks, in general, with a precision better than \pm 0.004 per cent per degree centigrade. ${ }^{\circ}$

The fork was driven by an electron tube, as shown in circuit diagram, Figure 7 . When the circuit is first closed the fork is set into vibration, the amplitude being increased as the circuit is brought into resonance. The vibration of the fork is feeble at first but serves to alter the reluctance of the circuit, thus causing a variation in the plate current which is further amplified by the regenerative action of the circuit. The amplification of the plate current thus produced and the consequent increase in the amplitude of the vibrations of the fork is limited by the power of the tube. A 5-watt electron tube is used in the circuit with a plate voltage of 300 volts and a filament current of 2.3 amperes. The tuning condenser has a range of $0.0015 \mu \mathrm{f}$. When not in use the tuning fork is protected by a box inclosing a drying agent $\left(\mathrm{CaCl}_{2}\right)$. A large bulb alcohol thermometer is hung directly over the tuning fork for temperature-correction readings.

\footnotetext{
6 For reference see H. M. Dadourian, "Characteristics of tuning forks," Phys. Rev., 13, p. 354, May, I919; and D. Dye, "The valve-maintained tuning fork as a precise time standard," Proc. Roy. Soc., 103; 1923. 


\section{RADIO-FREQUENCY GENERATING SETS.}

The generating sets used in stepping up from the frequency of the tuning-fork generating set have a range from 3.4 to 5 ,000 kilocycles. A circuit diagram is shown in Figure 8 . They are of the same type, each using a single 250-watt electron tube. The plate voltage was obtained from high-voltage batteries giving a constant current of small value. From 500 to 700 volts were applied to each generating set from separate batteries to insure against reaction. A detailed description of the highvoltage batteries ${ }^{7}$ has been given by J. L. Preston and E. L. Hall. The filament current was supplied by two 30-volt 4-

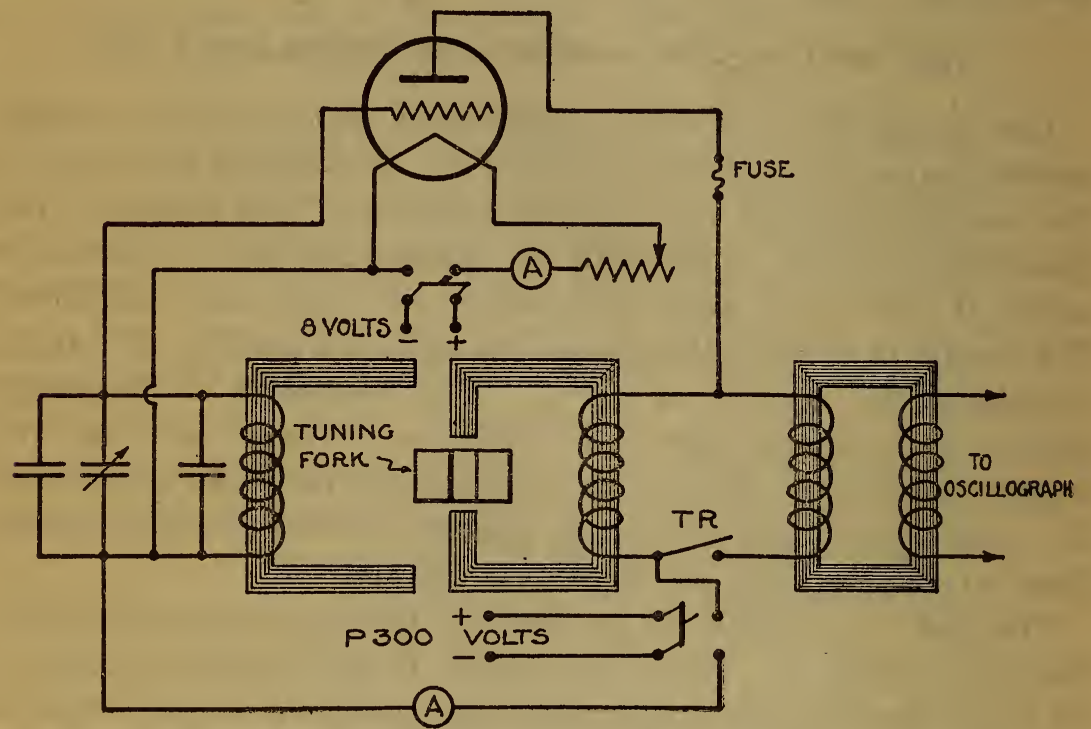

FIG. 7.-Diagram of the circuit network of tuning fork with electron-tube drive.

ampere batteries used in parallel to obtain a steady current. The generating sets were provided with two sets of inductance coils and three variable condensers from 0.002 to $0.05 \mu \mathrm{f}$ for coarse adjustments. Variable air condensers from 300 to $\mathrm{I}, 000 \mu \mu \mathrm{f}$ with slow-motion screws were used for the finer adjustments.

The generating sets were shielded by wire-screen cages which were grounded. Their condensers were fitted with long handles made of insulating material leading through the cages. All leads were inclosed in grounded metal cases, and the batteries in the room were shielded.

7 "A high-voltage storage battery for use with electron-tube generators of radio-frequency currents," by J. L. Preston and E. L. Hall, Jour. Opt. Soc. Amer., 6, p. 177, March, I922. 


\section{THE CATHODE-RAY OSCILLOGRAPH.}

The cathode-ray oscillograph ${ }^{8}$ as used to compare the frequencies of two electron-tube generating sets is shown in Figure 9. It has been described in detail by L. M. Hull. In the cold-cathode tubes used for this work I 5,000 volts or more were applied to the cathode, and the electron stream thus excited was reduced by a diaphragm with a single aperture to give a small bright spot on the

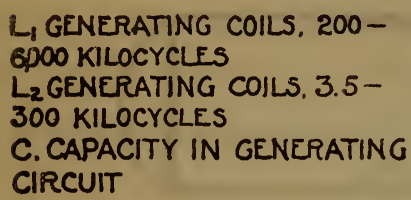

L, GENERATING COILS, $200-$ 6DOO KILOCYCLES $L_{2}$ GENERATING COILS, 3.5 300 KILOCYCLES C. CAPACITY IN GENERATING CIRCUIT

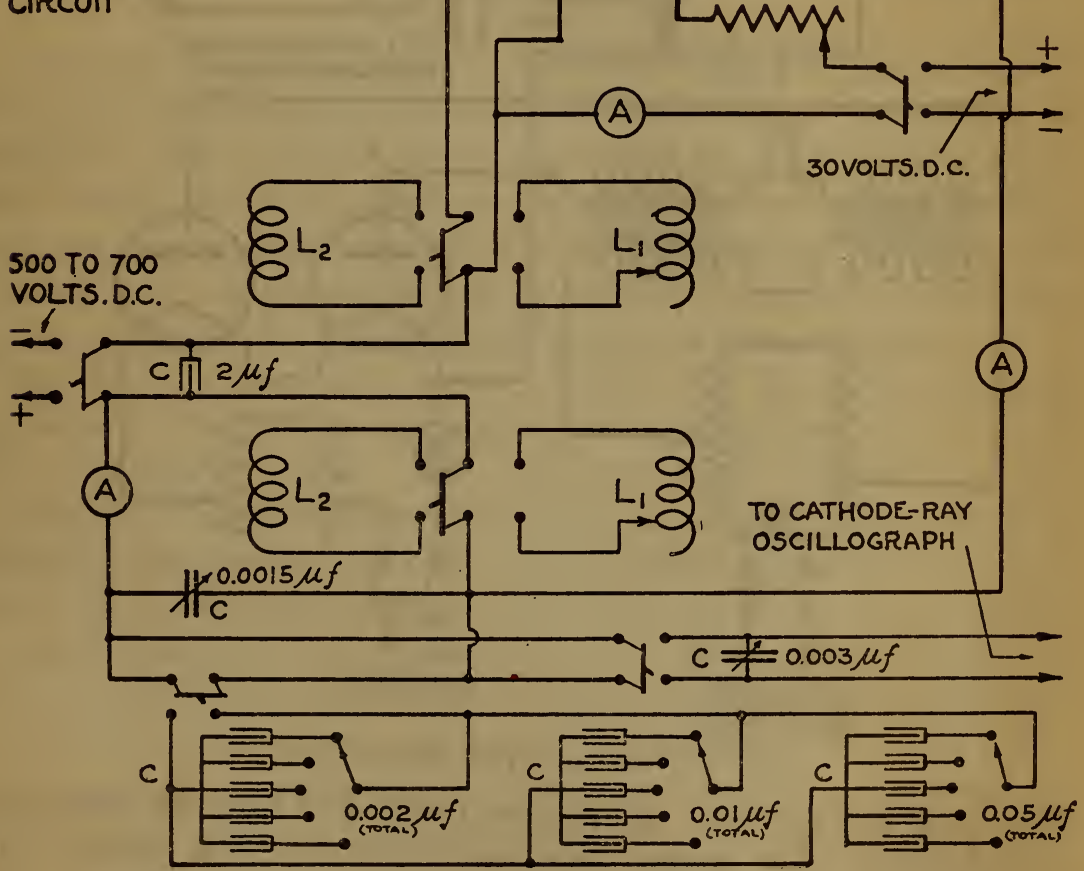

FIG. 8.-Panel type generating set used in the frequency standardization.

Two radio-frequency generators of this type were used. Each had a range from 3.4 to 6,000 kilocycles per second.

fluorescent screen. Alternating electric fields from the generating sets were applied at right angles to each other, and the electron stream by means of condenser plates. Lissajous figures could thus be formed on the fluorescent screen. Figure Io shows the oscillograph circuit with current supply and rectifying device, a 220-volt, 6o-cycle alternating-current line, and two transformers

${ }^{8}$ Reference I, D. 446. 
Scientific Papers of the Bureau of Standards, Vol. 19

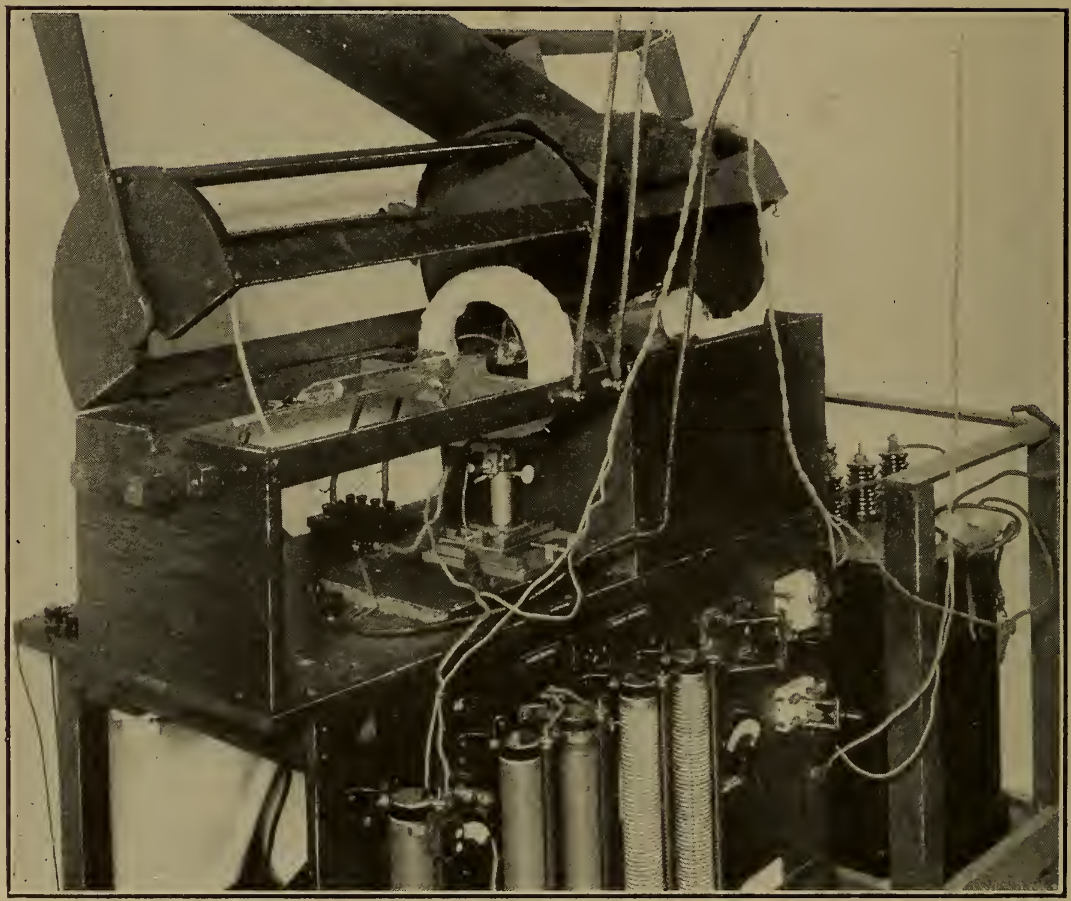

FIG. 9.-The cathode-ray oscillograph, with cover raised to show tube.

Lissajous figures are produced on the screen of the tube by voltages of frequencies having an integral relation. 
furnished the high voltage which was rectified by two kenotronrectifier tubes. A choke coil was used in the circuit and the anode of the tube was grounded through a water resistor of approximately 2 megohms.

The first cathode-ray tube used was a meter in length. It had a high vacuum requiring over 20,000 volts to produce a bright

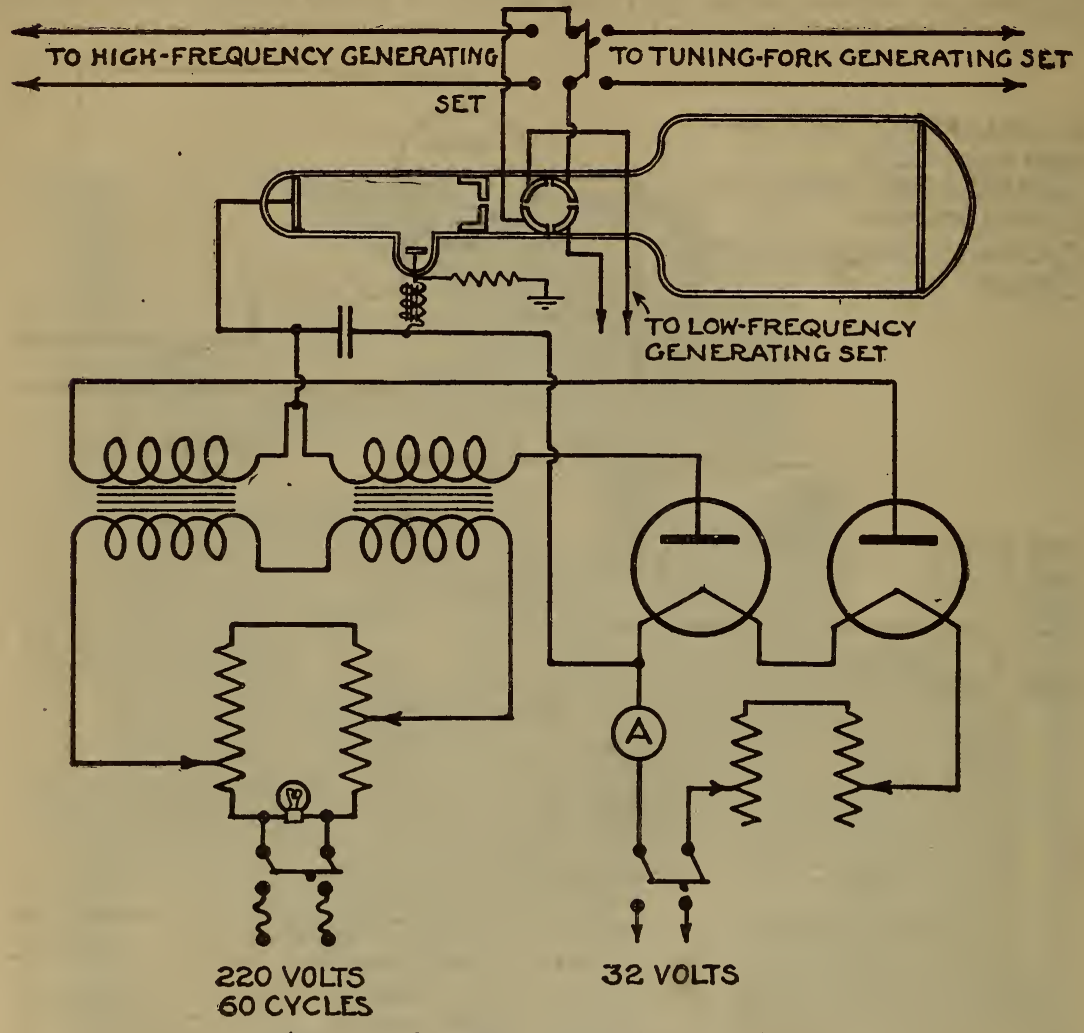

FiG. I0.-Cathode-ray tube and mounting.

spot $\mathrm{I} \mathrm{mm}$ in diameter. It was practically free from the tendency to flash over. The second tube was about $75 \mathrm{~cm}$ in length. It was operated at approximately 18,000 volts and required a concentrating coil of 500-ampere turns to reduce the size of the spot to $\mathrm{I} I / 2 \mathrm{~mm}$ in diameter. The condenser plates used to apply the deflecting voltages to the tube were copper-foil strips 1.5 by 9 cm. They were mounted directly on the glass between the diaphragm and the bulb.

\section{PROCEDURE.}

The calibration as outlined was accomplished in three steps: (I) Determination of the wave-meter settings corresponding to 
known frequencies between I3.I and 620 kilocycles by the direct comparison of the generating sets with the tuning-fork generating set and the drawing of the calibration curves from the values of $L_{\mathrm{p}}$ and $C_{\mathrm{o}}$ thus obtained. (2) Standardization of wave meter, using the two remaining coils with no fixed condensers, by a similar method using perviously standardized coils as a basis for frequency comparison, 620 to 4,900 kilocycles. (3) Determination of wave-meter setting corresponding to known frequencies below I3.I kilocycles employing fixed condensers in the wave meter. The basis of frequency comparison was the fork and previously calibrated coils.

\section{DIRECT COMPARISON WITH TUNING FORK FOR LOW-FREQUENCY STANDARDIZATION.}

The work of standardization was begun using the 5-layer bankwound coil of approximately I 27,000 microhenries. A 3-turn coil coupled to this inductor and in series with the wall galvanometer and crystal detector served as the resonance-indicating device. The coupling between the coils was sufficiently loose to insure the reaction being inappreciable, the settings of the variable condenser being unaffected by slight displacements of the coupling coil.

The wave meter was coupled loosely to the low-frequency generating set whose frequency was to be compared with that of the tuning-fork circuit. The capacity of the cathode-ray deflecting plates, which were connected in parallel with the condenser of the generating set, was relatively small, so that any small change in the condition of the tube had a negligible effect on the frequency of the generating set. The tuning-fork generating set, which was connected through a transformer to the other set of deflecting plates, was tuned to resonance with the fork. This was done by adjusting a variable air condenser until beats between the impressed and natural frequency of the fork appeared. This could be detected aurally and was further indicated by the milammeter in the plate circuit which showed the presences of beats very nicely. The tube was always used with the same plate voltage. Small changes in plate current-that is, in the amplitude of the fork-appeared to have a negligible effect on the frequency of the fork as shown by tests. Lissajous figures showed no change with small forced changes of current, etc. If the circuit is left so closely adjusted that the beats are slow they will automatically die out. 
To tune the low-frequency generating set to a frequency where the Lissajous pattern could be readily found, a tentative calibration of the wave meter was made by comparison with the previous standards of the bureau. The wave meter was set at approximately the desired point, the low-frequency generating set tuned to it, and small adjustments made until the pattern appeared. For low ratios the pattern was readily recognizable, but for the more complex ratios, although recognizable as a pattern, the ratio could be selected only with great difficulty due to the blurring of the lines. The tentative calibration was relied upon to determine the right frequency ratio corresponding to the pattern. It was found possible by this method to use ratios as high as $22: \mathrm{I}$.

As the generating set was brought to the desired frequency, the pattern on the field appeared to be in rotation. The rate of rotation decreased as the generating set was gradually adjusted to the frequency ratio, and finally when the exact multiple relation was obtained the pattern stood still. A difference of one cycle per second from the lower frequency was sufficient to cause one rotation per second. A slow motion of the pattern was thus not objectionable, since at the frequency measured the percentage error was negligible. When the pattern was located the wave meter was detuned in order to prevent any reaction effect, and the generating set adjusted until the pattern was sufficiently stationary, then the wave meter was again tuned to the generating set and a reading taken. If the pattern was watched during this process, a slight reaction effect could be noticed, the pattern starting to rotate as the wave meter was being brought into resonance, coming to a standstill when the resonance point was reached, and again rotating if the resonance point was passed. This reaction could, of course, be decreased by decreasing the coupling, but the effect was small, and it was decided that less error was introduced in this way than by decreasing the coupling to a point where the galvanometer deflections became difficult to read. Settings of the wave meter were made by decreasing and then by increasing the capacity, the reaction in the two cases tending to doubly change the frequency of the generating set, but no change could be noticed in the setting - that is, the error introduced was negligible. Under certain conditions, however, recognizable interaction could be noted beween the two generating sets operating through the cathode-ray oscillograph. This is further discussed under observational difficulties. 
Each reading was checked by independent settings. The tuning-fork circuit was thrown out of resonance with the fork and retuned, the low-frequency generating set readjusted, and the wave meter again retuned. In this manner some 5 to 30 frequency determinations were obtained on the circuit with each coil and the variable air condenser.

A summary of the results from one low-frequency generator pattern ratio is given in the following table as illustrative of data obtained. The two runs were made by different observers and on different days.

TABLE I.-Summary of Observational Results.

\begin{tabular}{|c|c|c|c|}
\hline \multicolumn{2}{|c|}{ Pattern ratios. } & \multirow{2}{*}{$\begin{array}{c}\text { Frequency } \\
\text { ratio. }\end{array}$} & \multirow{2}{*}{$\begin{array}{c}\text { Difference } \\
\text { between } \\
\text { two runs } \\
\text { as shown } \\
\text { by wave- } \\
\text { meter } \\
\text { read- } \\
\text { ing. }\end{array}$} \\
\hline $\begin{array}{l}\text { Low- } \\
\text { frequency } \\
\text { generator. }\end{array}$ & $\begin{array}{c}\text { High- } \\
\text { frequency } \\
\text { generator. }\end{array}$ & & \\
\hline \multirow[t]{2}{*}{$1: 20$} & $\begin{array}{l:l}1 & 12 \\
1 & 13 \\
1 & 14 \\
1 & 15 \\
1 & 16\end{array}$ & $\begin{array}{l}240 \\
260 \\
880 \\
300 \\
320\end{array}$ & $\begin{array}{c}\text { Per cent. } \\
0.06 \\
.03 \\
.08 \\
.01 \\
.03\end{array}$ \\
\hline & 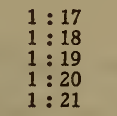 & $\begin{array}{l}340 \\
360 \\
380 \\
400 \\
420\end{array}$ & $\begin{array}{l}.00 \\
.00 \\
.04 \\
.00 \\
.00\end{array}$ \\
\hline
\end{tabular}

\section{THE CALIBRATION CURVES.}

In drawing the calibration curves the following procedure was followed to obtain intermediate points when Lissajous figures were at some considerable frequency intervals. The distributed capacity and pure inductance of the coil and leads were computed from the known value of the capacity of the variable air condenser in the circuit when resonant at a given frequency. The following formula was used:

$$
f=\frac{\mathrm{I}}{2 \pi \sqrt{L_{\mathrm{p}}\left(C+C_{\mathrm{o}}\right)}}
$$

$f=$ frequency in kilocycles per second from observational data.

$C=$ capacity in micromicrofarads as given by precise measurements of the variable condenser at a low frequency of charge and discharge. (The condenser was especially constructed to have a capacity virtually independent of the frequency.) $C_{0}=$ distributed capacity of the coil and leads calculated from two frequencies with the corresponding values of capacity by using the above formula twice. $L_{\mathrm{p}}=$ pure inductance from the formula. 
For each two frequency determinations, of which there were 5 to 30 for each coil in the circuit, a value of $C_{o}$ was found. The value of $\mathrm{C}_{\mathrm{o}}$ giving the least mean deviation was then used to obtain a tentative value of $L_{\mathrm{p}}$ from the formula. Trial values of $C_{\mathrm{o}}$ higher and lower than the above were then tried until the point of minimum average deviation of the tentative values of $L_{\mathrm{p}}$ was reached. This value of $L_{\mathrm{p}}$ was then used to calculate the distributed capacity from the formula. The weighted mean of values of $C_{\mathrm{o}}$ so obtained check the value of $C_{\mathrm{o}}$ used to determine $L_{\mathrm{p}}$. Having determined the value of $C_{\mathrm{o}}$ and $L_{\mathrm{p}}$, the same formula was used to determine the frequency of the circuit for other values of the variable air condenser $C$. These values were determined for every two degrees of the condenser scale and plotted against frequency. (See fig. Ir.) The probable error in the computation was found by the usual formula

where

$$
p=0.6745 \sqrt{\frac{v^{2}}{n(n-1)}}
$$

$p=$ probable error;

$v=$ deviation from mean;

$n=$ number of readings.

It was slightly less than 0.02 per cent for the pure inductance and in determining the distributed capacity o.I $\mu \mu \mathrm{f}$.

\section{HIGH-FREQUENCY STANDARDIZATION.}

The wave meter was standardized to a frequency of 22,000 cycles by this process, using Lissajous pattern ratios up to $22: \mathrm{I}$, which was practically the limit of visibility for the Lissajous figures in the cathode-ray tube used. For this reason the next step beyond this frequency required the use of the third, or highfrequency generating set. This generating set could be compared with the low-frequency generating set alternately with the tuning fork by means of a mercury switch connected to the cathoderay oscillograph. The low-frequency generating set was set to some multiple of the tuning fork, the switch thrown to the highfrequency generating set, which was in turn tuned to successive multiples of the low-frequency generating set. After each reading a check was made with the tuning fork, following the same method as given above. As the frequency was increased, it became more difficult to set upon a pattern since a very small percentage change in frequency would cause a rapid motion of the pattern. For example, five rotations per second of the pattern, which is fairly rapid, would give a percentage error of 0.005 per 
cent at roo kilocycles, and only 0.0005 per cent at $\mathrm{I}, 000$ kilocycles per second. Special fine-adjustment condensers and slowmotion devices on the generating sets were necessary to obtain a stationary pattern at high frequencies. While it was quite possible to maintain the generating sets at a constant frequency for some little time, they were found to be extremely susceptible to

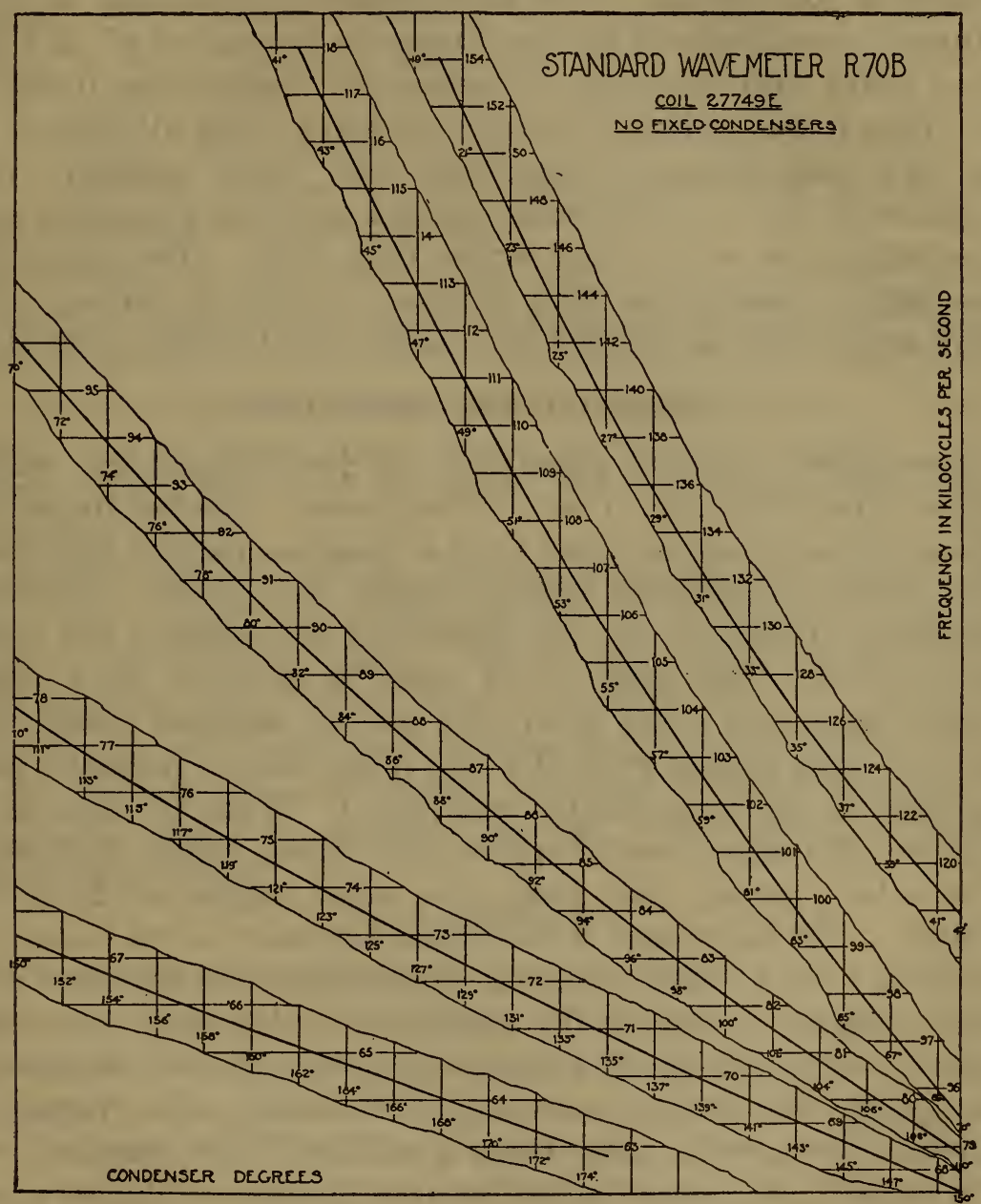

FIG. II. - A calibration curve as drawn for the standard wave meter $R 70 B$. Condenser degrees plotted on abscissas and frequency on ordinates.

voltage changes, either in the plate or filament circuits. Work at high frequencies was impossible unless the batteries were well charged. Perhaps more trouble was experienced from this than any other cause.

By this means four of the six inductors were standardized in the wave-meter circuit and calibration curves drawn from data 
obtained. The coil and variable condenser of the highest frequency thus standardized was then used as the standard for further work, the tuning fork being no longer used.

The method followed was very similar to the preceding. The low-frequency generating set was set to a suitable frequency reading on the wave meter using the newly standardized coil and condenser combination. The high-frequency generating set was adjusted to multiples of the low-frequency generating set and the wave meter with the higher frequency coil combination tuned to it. Thus it was necessary to tune the wave meter alternately to the two radio-frequency generating sets. Some difficulty was experienced due to a noticeable reaction upon the generating sets in wheeling the wave meter across their fields. The apparatus was finally arranged so that, without varying its carriage, the wave meter could be coupled by a slight turn to either generator.

\section{OBSERVATIONAL DIFFICULTIES.}

Interaction occurred principally at low frequencies, where simple ratios such as $2:$ I or $3:$ I were used. The low-frequency generating set could be tuned until a Lissajous pattern appeared; then further adjustment changes made, the pattern remaining absolutely stationary, the one generating set carrying the other along with it. This effect could easily be detected, since under normal conditions if the generating set was adjusted slowly, the pattern would appear, gradually slow down, and as gradually pick up speed as the ratio relation was passed. While in the case of reaction, the pattern would appear, slow down, remain stationary over a long period, then jump into rapid motion or disappear entirely. For this reason it was found necessary to use fractional ratios as $3: 2,5: 2$, etc., since at these frequencies the effect was almost absent. A test of the magnitude of this effect was easily made by adjusting one of the generating sets, first by decreasing its capacity, and then by increasing it, the change in the frequency as given by the wave meter being a measure of the reaction.

A rather curious effect noticed was the presence of blurred counterparts of the original figure which appeared when the generating set was not quite tuned to the proper frequency. An explanation was offered by R. T. Cox, formerly of this bureau, who attributed the effect to the pulsating character of the voltage supplied to the cathode-ray tube. He suggested that the resultant change in the velocity of the electrons down the tube would cause a corresponding pulsation in the amplitude of the deflection, thus modulating the principal deflection frequency. This would produce 
the equivalent of three components, a single strong component of the frequency of the generating set and two relatively weak components on each side of the principal one and differing from it by the modulating frequency. The voltage was obtained from a 6o-cycle line which supports the proposed explanation in that so far as could be measured the spacing between patterns was 60 cycles. The situation is actually even more involved than this owing to the presence of harmonics which produce patterns of more complex ratios. The ratios of these were difficult to recognize owing to their complexity and the fact that the harmonics were materially weaker than the fundamental. The side figures were consequently much blurred.

Some difficulty was experienced with the resonance frequency of the galvanometer circuit at high frequencies. The resonance of the galvanometer circuit thus prevented measurements being taken at a certain frequency and at times it was found necessary to practically halt all other high-frequency work in the building. The interference appeared to be partly due to the use of the same grounding system.

Another difficulty at high frequencies was the ionization of the gas in the cathode-ray oscillograph tube by the high potential applied to the deflecting plates. This was shown by the bulb of the tube glowing with a bluish white or lavender light. A radio-frequency condenser connected in series with the generating set reduced the potential and stopped the glow. It also furnished a convenient means of adjusting the size of the deflection on the screen of the tube.

\section{SUMMARY.}

The cathode-ray oscillograph has been shown to be a satisfactory and extremely precise means of obtaining frequency ratios for establishing values of radio-frequencies in terms of an audiofrequency. The primary standard wave meter of the bureau was standardized in terms of the frequency of a tuning fork having a frequency of $\mathrm{I}, 024.2$ cycles per second by this means. The method as used was somewhat elaborate, requiring the simultaneous use of three electron-tube generating sets and a cathode-ray tube. The limitations in the accuracy attainable appear to be entirely in the audio-frequency source used as the basis of measurement and in the wave meter.

WASHINGTON, November 28, 1923 . 


